\title{
Utilización de placas de ELISA de alta y de baja avidez en la determinación de anticuerpos contra la toxina de cólera
}

\author{
Elizabeth Castañeda ${ }^{1}$, Magaly Chinchilla ${ }^{1}$, David A. Sack², Ann Mari Svernnerholm³
}

\begin{abstract}
Resumen
Los sueros de un estudio de inmunogenicidad de una vacuna oral de células enteras de Vibrio cholerae $\mathrm{O} 1$ más la subunidad $\mathrm{B}$ recombinante de la toxina $(\mathrm{CE} / \mathrm{sBr})$ fueron procesados para la determinación de anticuerpos antitoxina de cólera en placas de ELISA de alta y de baja avidez. Los títulos de anticuerpos antitoxina, de la clase lgG, de los sueros prevacunales estuvieron incrementados de 5 a 7 veces, en las placas de alta avidez, comparados con los títulos obtenidos en las placas de baja avidez. Igualmente, los títulos de los sueros post vacunales fueron 3 veces superiores cuando se realizó la misma comparación de placas. Por consiguiente, la tasa de seroconversión medida en las placas de alta avidez fue de $39 \%$, comparada con $68 \%$ al utilizar las placas de baja avidez. El suero control de alto título de anticuerpos no detectó el problema. Se sugiere utilizar placas de baja avidez al determinar anticuerpos contra la toxina de cólera por la técnica de ELISA.
\end{abstract}

\section{The use of low and high binding ELISA plates in the determination of cholera antitoxin antibodies}

Sera from an immunogenicity study of killed oral cholera vaccine was tested in high and low binding Elisa plates. High binding plates yielded 5 to 7 -fold higher prevaccination IgG antitoxin titres and about 3-fold higher post-vaccine antitoxin titres, but lower sero-conversion rates (39\% for high and $68 \%$ for low binding plates) when they were compared with low binding plates, because the pre-vaccine titres were relatively higher than the post-vaccine titres. The high titre serum, being used as a standard control serum in each ELISA plate, did not detect the problem. We suggest using lowbinding plates when carryng out ELISA assays for cholera antitoxin antibodies.

Durante la realización de un ensayo clínico de inmunogenicidad de la vacuna oral de células enteras de Vibrio cholerae 01 más la subunidad $B$ recombinante de la toxina $(\mathrm{CE} / \mathrm{SBr})$ realizado en Barranquilla $(1,2)$, se observó que el porcentaje de seroconversión de los títulos antitoxina fue más bajo que el informado en otros estudios con la misma vacuna (3-7). La posible explica- ción para la diferencia en la respuesta no parecía ser de carácter biológico; por tanto, con el fin de buscar una explicación técnica que aclarara la diferencia, se decidió revaluar el método de ELISA empleado para determinar los títulos de anticuerpos antitoxina y dilucidar así las diferencias observadas.

Los reactivos y el método de ELISA que habían

${ }^{1}$ Instituto Nacional de Salud, Santa Fe de Bogotá, Colombia,

${ }^{2}$ The Johns Hopkins University, Baltimore, MD, Estados Unidos,

${ }^{3}$ University of Goteborg, Goteborg, Suecia.

Recibido para su publicación: 1 de 1998. - Aprobado para publicación: 6 de mayo de 1998. 
sido empleados fueron idénticos a los previamente informados (8), excepto por las características de avidez de las placas de ELISA. Por tanto, se diseñó un estudio para determinar si las características de unión de las placas podrían afectar en forma significativa los títulos antitoxina $y$, por ende, la seroconversión, es decir, el incremento en el título de anticuerpos de los sueros posvacunales comparado con los prevacunales. Los resultados sugieren que, en las placas de alta avidez, los títulos de anticuerpos antitoxina son mayores, tanto en los sueros pre y posvacuna, pero la diferencia fue más marcada con los sueros prevacuna. Por consiguiente, la proporción de sueros pareados con seroconversión fue menor en las placas de alta avidez. Estas diferencias no fueron detectadas cuando se incluyó, en cada placa, un suero control con alto título ya que éste indicó que la prueba estaba dentro del límite de aceptación con las dos clases de placas.

\section{Materiales y métodos}

Muestras de suero. Se incluyeron las muestras de suero de dos grupos de voluntarios. El primer grupo incluyó 50 muestras pareadas de 28 personas que recibieron la vacuna y de 22 que recibieron el placebo en un estudio, doble ciego, controlado con placebo, de inmunogenicidad de la vacuna de $\mathrm{CE} / \mathrm{sBr}$ realizado en Barranquilla (2). Las muestras de suero capilar fueron recolectadas antes de la primera dosis y 15 días después de la segunda dosis.

El segundo grupo de muestras de suero fueron recolectadas por punción venosa de 20 voluntarios de Bogotá que recibieron la misma vacuna en un estudio abierto donde no se incluyó el placebo. Las muestras de suero (5 por cada voluntario) fueron obtenidas semanalmente, a partir de la semana 0, día de la primera dosis hasta el día 28 , dos semanas después del suministro de la segunda dosis (9).

Vacuna. La vacuna (SBL vaccunas $A \circ B$, Stockholm) consistió de $10^{11}$ células enteras muertas de Vibrio cholerae 01, más $1 \mathrm{mg}$ de la subunidad $B$ recombinante de la toxina (CE/ $\mathrm{SBr}$ ) y fue similar a la empleada en un estudio previo en Bangladesh (3), excepto que en esta vacuna la subunidad $B$ de la toxina fue obtenida a partir de una cepa de Vibrio cholerae que produce solo la subunidad $B$ pero no la holotoxina (5). El placebo (SBL vaccines A, B, Stockholm) consistió de células muertas de Escherichia coli K12 ajustada a la misma densidad óptica que la vacuna (3). La vacuna fue dada por vía oral en una solución de bicarbonato y ácido cítrico (Samarín), el volumen de la solución fue adaptado según la edad de los participantes $(2,9)$.

Microplacas. Se emplearon microplacas de 96 pozos, de fondo plano, de las siguientes especificaciones: placas de alta avidez, Immulon 2 (Dynatech) y Corning; así mismo, placas de baja avidez, Immulon 1 (Dynatech).

Método de ELISA. Los títulos de antitoxina de IgG e IgA fueron determinados por un micrométodo (8). Brevemente, las microplacas fueron cubiertas con $100 \mu \mathrm{L}$ del gangliósido Gm1 (galactosa $\beta 1 \rightarrow 3 N$ - acetil glucosamina $\beta 1$ (ácido $3 \mathrm{~N}$-acetil neuramínico $\alpha 2 \rightarrow 3$ ) $\rightarrow$ glucosa - ceramida ) $(0,3 \mathrm{nmol} / \mathrm{mL}$, Sigma), diluido en solución tampón fosfato salino (PBS), incubadas toda la noche y almacenadas a $4^{\circ} \mathrm{C}$, por un máximo de dos semanas. Al momento del uso fueron lavadas 3 veces con PBS, bloqueadas con $150 \mu \mathrm{L}$ de albúmina sérica bovina (BSA) al $0,1 \%$ en PBS e incubadas a $37^{\circ} \mathrm{C}$ por 30 minutos y lavadas una vez más con PBS. Posteriormente, a cada pozo se le adicionaron $100 \mathrm{~mL}$ de la subunidad $B$ de la toxina de cólera (Universidad de Goteborg, Suecia) $(0,5 \mu \mathrm{g} / \mathrm{mL})$ diluida en BSA-PBS y se incubaron las placas durante 60 minutos a temperatura ambiente. Después de lavar 3 veces con Tween 20 al $0,05 \%$ en PBS, se adicionaron las muestras de suero diluidas en BSA-PBS-Tween, en un volumen final de $100 \mu \mathrm{L}$ por pozo (la dilución inicial fue 1:60 y la dilución final 1:131.220, con un volumen final de $100 \mu \mathrm{L}$ por pozo), se incubaron por 30 minutos a temperatura ambiente. Las placas se lavaron nuevamente 3 veces con PBS-Tween y se adicionaron, por pozo, $100 \mu \mathrm{L}$ de anti-IgG o antiIgA humano conjugado con peroxidasa de rábano picante (Jackson), diluidos en $0,1 \%$ de BSA-PBS-Tween. Finalmente, las placas se lavaron con PBS-Tween y se adicionó el substrato 
compuesto de o-fenilendiamina (OPD) $(1 \mathrm{mg} / \mathrm{mL})$ (Sigma) diluido en solución de citrato de sodio, $\mathrm{pH} 4,5$ más peróxido de hidrógeno al $30 \%(4 \mu \mathrm{L}$ $10 \mathrm{~mL}$ ). A los 20 minutos, las placas fueron leídas en un lector de ELISA, a una densidad óptica (DO) de $450 \mathrm{~nm}$. Los títulos se calcularon con un programa de computador para interpolar la dilución del suero que daba una OD de 0,4 por encima de la línea base. Los sueros pre- y posvacuna fueron probados simultáneamente en la misma microplaca. A la lectura de DO de cada pozo se le restó la DO del pozo del blanco, al cual se agregó los mismos reactivos que a los pozos de las muestras problemas excepto la muestra de suero. Se empleó como control positivo, un suero con un título de anticuerpos antitoxina de 1:4.000.

La seroconversión se definió como el incremento en el título, mayor o igual a 1,5 veces, entre los dos sueros; este dato fue previamente estandarizado (3).

\section{Resultados}

La media geométrica (MGT) de los títulos de anticuerpos antitoxina, de la clase IgG en voluntarios de los grupos $1(n=28)$ y grupo $2(n=20)$ que recibieron la vacuna oral anti-cólera $\mathrm{CE} / \mathrm{sBr}$ está expresada en el cuadro 1, en relación con la avidez de las placas de ELISA empleadas.

La MGT de los sueros fue más alta en las placas de alta avidez, comparada con la obtenida en las placas de baja avidez (cuadro 1); sin embargo, el incremento en la MGT fue menor, en las placas de alta avidez comparado con las de baja avidez en los dos grupos estudiados (cuadro 1). La relación de los títulos (placas de alta avidez a placas de baja) fue mayor para los sueros prevacuna que para los sueros posvacuna (cuadro 1).

En la cuadro 2 se expresan las tasas de seroconversión de los títulos de anticuerpos antitoxina de las clases IgG e IgA en los dos tipos de placas. Para los dos grupos de sueros, la tasa de seroconversión fue significativamente más alta cuando se utilizaron las placas de baja avidez.

La cuadro 3 muestra los títulos de $\lg G$ y de $\lg A$ de muestras seriadas de dos voluntarios del grupo 2, incluidos en los análisis de las tablas 1 y 2 , los cuales recibieron dos dosis de vacuna. Nuevamente, el incremento en los títulos fue consistentemente mayor cuando se realizaron los ensayos con las placas de baja avidez.

En general, existió una buena correlación entre las placas de alta y baja avidez $(r=0,86(0,77$ $0,91)$. Sin embargo, los sueros con títulos bajos $(1: 300)$ en las placas de baja avidez, presentaron menor correlación $(r=0,24(-0.071-0,51))$ que los sueros con títulos altos $(r=0,89(0,86-$ $0,96)$. Por tanto, se observó que los sueros con títulos bajos tienden a dar resultados altos en las placas de alta avidez.

Cuadro 1. Media geométrica de los títulos de anticuerpos antitoxina de clase IgG en personas* que recibieron la vacuna oral anti-cólera $\mathrm{CE} / \mathrm{sBr}$ en placas de ELISA de alta y baja avidez.

\begin{tabular}{|c|c|c|c|c|c|c|}
\hline \multirow[b]{2}{*}{ Grupo $1^{*} \quad n=28$} & \multicolumn{2}{|c|}{$\begin{array}{l}\text { Placas de alta avidez } \\
\text { Pre-vacuna Pos-vacuna }\end{array}$} & \multicolumn{2}{|c|}{$\begin{array}{l}\text { Placas de baja avidez } \\
\text { Prevacuna Pos-vacuna }\end{array}$} & \multicolumn{2}{|c|}{$\begin{array}{l}\text { Tasa placas alta/baja avide } \\
\text { Pre-vacuna Pos-vacuna }\end{array}$} \\
\hline & $537^{\star *}$ & 954 & 102 & 275 & 5,26 & 3,46 \\
\hline Error estándar & $474-608$ & $843-1081$ & $95-109$ & $281-319$ & & \\
\hline Incremento & 1,77 & 2,7 & & & & \\
\hline Grupo $2^{*} \quad n=20$ & 524 & 660 & 76 & 219 & 6,89 & 3,01 \\
\hline Error estándar & $457-602$ & $452-966$ & $67-111$ & $178-268$ & & \\
\hline Incremento & 1,25 & 2,88 & & & & \\
\hline
\end{tabular}

*El grupo 1 estaba constituido por muestras de suero del estudio de inmunogenicidad en Barranquilla y el grupo 2 por muestras de voluntarios de Bogotá.

**Los números son las medias geométricas de los títulos (MGT) y los límites inferiores y superiores del error estándar de la MGT. 
Cuadro 2. Tasas de seroconversión* de títulos de anticuerpos antitoxina de las clases IgG y IgA en placas de ELISA de alta y baja avidez **.

\begin{tabular}{|c|c|c|c|c|}
\hline & \multicolumn{2}{|c|}{ Placebo } & \multicolumn{2}{|c|}{ Vacuna } \\
\hline & $\begin{array}{c}\text { Placas de alta } \\
\text { avidez }\end{array}$ & $\begin{array}{c}\text { Placas de baja } \\
\text { avidez }\end{array}$ & $\begin{array}{c}\text { Placas de alta } \\
\text { avidez }\end{array}$ & $\begin{array}{c}\text { Placas de baja } \\
\text { avidez }\end{array}$ \\
\hline \multicolumn{5}{|l|}{ 1. Incremento en los títulos IgG } \\
\hline Grupo 1 & $6 / 22(27 \%)$ & $5 / 22(23 \%)$ & $11 / 28(39 \%)$ & $19 / 28(68 \%)^{\star \star \star}$ \\
\hline Grupo 2 & NP & NP & $11 / 20(55 \%)$ & $14 / 20(70 \%)$ \\
\hline \multicolumn{5}{|l|}{ 2. Incremento en los títulos $\lg A$} \\
\hline Grupo 2 & NP & NP & $12 / 20(60 \%)$ & $16 / 20(80 \%)$ \\
\hline
\end{tabular}

* La seroconversión se definió como un incremento mayor o igual a 1,5.

** Las placas de alta avidez fueron Corning para el grupo 1 e Immunol 2 (Dynatech) para el grupo 2.

*** Al procesar las muestras en placas de baja avidez, una alta proporción seroconvirtió en forma significante. $\left(X^{2}=4,51, p=0,33\right.$ prueba de Mantel Haentzel).

NP: no probados: el placebo no fue dado a voluntarios.

\section{Discusión}

Este estudio demostró que la tasa de seroconversión observada varió según la clase de placa de ELISA empleada, de alta o de baja avidez. En estudios previos de anticuerpos anti toxina colérica, los datos serológicos fueron obtenidos empleando las placas de baja avidez (1, $3,7,10)$. Cuando se empezaron a distribuir las placas de alta avidez, algunos laboratorios las empezaron a usar, asumiendo que con ellas se podría mejorar la técnica de ELISA. Infortunadamente, los resultados que se obtuvieron en este ensayo, con las dos placas, no son comparables. Las tasas de seroconversión fueron significativamente menores con las placas de alta avidez, principalmente debido al alto título obtenido con los sueros prevacuna. Las diferencias observadas fueron aplicables a ambas determinaciones, tanto a los anticuerpos de la clase IgG como a los de IgA.

Las placas de baja avidez, Immulon 1 (Dynatech), son recomendadas para la adsorción de anticuerpos y de compuestos que contienen lípidos en un ambiente hidrofóbico, como son glicolípidos, lipopolisacáridos y lipoproteínas y, generalmente, exhiben baja unión no específica; por esta razón, presentan bajo ruido de fondo. Por el contrario, las placas Immulon 2 (Dynatech), están diseñadas para estimular la unión de proteínas; en un medio hidrofílico, estas placas proveen una excelente unión de antígenos altamente purificados y pueden ser usadas en ensayos de proteínas, péptidos y ácidos nucleicos (11).
Las placas de alta avidez utilizan poliestireno que ha sido tratado para incrementar la unión de las proteínas y se han diseñado para incrementar la sensibilidad en los ensayos que detectan antígeno. Sin embargo, cuando se emplean en ensayos que detectan anticuerpos, como este estudio lo demostró, las placas de alta avidez pueden incrementar la lectura de densidad óptica, dando títulos altos, con el agravante de que el incremento en la lectura puede ser proporcionalmente mayor en sueros pre-vacuna. Esta misma observación fue descrita en un estudio realizado por Shekarchi y colaboradores al determinar anticuerpos antiToxoplasma; al emplear diferentes clases de placas, de baja y alta avidez, demostraron que esta última clase presenta un incremento de la lectura de DO comparada con las de baja avidez o placas no tratadas (12).

El control de calidad empleado para validar el ensayo incluyó un suero control estándar en cada placa de ELISA. Sin embargo, este procedimiento no pudo detectar el problema observado en este estudio, porque el suero estándar tenía un título alto de anticuerpos y, por lo tanto, dio resultados similares en las dos clases de placas. Esta observación no permitió detectar el problema al inicio del estudio, el cual se hizo aparente cuando los resultados se compararon con los obtenidos en otros estudios. De ahí, la importancia de incluir en la prueba un suero control estándar con título medio de anticuerpos para detectar esta clase de problemas. 
Cuadro 3. Medias geométricas de los títulos (rango de error estándar de la media) de anticuerpos antitoxina de cólera de las clases IgG y IgA en los voluntarios del grupo 2 que recibieron vacuna.

\begin{tabular}{lcccc}
\hline $\begin{array}{l}\text { Días de } \\
\text { colección de } \\
\text { suero }\end{array}$ & $\begin{array}{c}\text { Placas de alta } \\
\text { avidez }\end{array}$ & $\begin{array}{c}\text { Incremento relativo } \\
\text { con los sueros } \\
\text { pre-vacuna }\end{array}$ & $\begin{array}{c}\text { Placas de baja } \\
\text { avidez }\end{array}$ & $\begin{array}{c}\text { Incremento relativo con } \\
\text { los sueros pre-vacuna }\end{array}$ \\
\hline IgG & $524(457-602)$ & & $76(67-86)$ & 1,1 \\
0 & $646(542-769)$ & 1,2 & $85(65-111)$ & 2,0 \\
7 & $708(604-830)$ & 1,3 & $155(129-186)$ & 2,6 \\
14 & $871(743-1021)$ & 1,7 & $200(163-245)$ & 2,9 \\
21 & $660(452-966)$ & 1,3 & $219(178-268)$ & \\
28 & $56(48-66)$ & & $20(17-22)$ & 1,4 \\
$\lg$ & $105(85-129)$ & 1,9 & $28(21-37)$ & 2,6 \\
0 & $123(98-155)$ & 2,2 & $52(39-70)$ & 3,7 \\
7 & $178(141-224)$ & 3,2 & $74(56-98)$ & 3,2 \\
14 & $115(83-158)$ & 2,0 & $65(51-81)$ & \\
21 & & & & \\
28 & 515 & & & \\
\hline
\end{tabular}

La vacuna fue dada en los días 0 y 14.

Con este estudio se podría plantear que las placas de ELISA de baja avidez permiten detectar un mayor número de individuos con anticuerpos contra la toxina de cólera; por tanto, es lógico su uso para poder comparar los resultados con los obtenidos en estudios previos. Una explicación para los resultados puede ser que las placas de alta avidez sean más sensibles para detectar los anticuerpos de baja avidez. Asumiendo que estos anticuerpos se presentan en sueros pre y posvacuna en iguales concentraciones y que la vacuna estimula la producción de anticuerpos protectores de mayor avidez, la detección de los anticuerpos de baja avidez producen un alto fondo que enmascara el desarrollo de los anticuerpos de mayor especificidad y avidez. Por este hallazgo, sería prudente utilizar placas de baja avidez e incluir sueros estándares con títulos bajos, medios y altos en las pruebas de detección de anticuerpos contra la toxina de cólera.

\section{Agradecimientos}

El estudio fue apoyado por la Organización Panamericana de la Salud y la vacuna fue donada por el National Bacteriology Laboratory, Stockholm, Sweden. A Kerstin Andersson de la Universidad de Göteborg por el valioso entrenamiento al personal del Instituto Nacional de Sa- lud en la estandarización de los ensayos serológicos.

A los doctores Alberto Concha, Ministerio de Salud; Alejandro Giraldo, Fundación Gillow, y Fernando de la $\mathrm{Hoz}$ del Instituto Nacional de Salud, Bogotá, Colombia.

\section{Referencias}

1. Clemens JD, Jertborn M, Sack DA, Stanton BF, Holmgren J, Khan MR, et al. Effect of neutralization of gastric acid on immune response to an oral B subunit, killed whole cell cholera vaccine. J Infect Dis 1986;154:175-8.

2. Concha A, Giraldo A, Castañeda E, Martínez M, de la Hoz F, Rivas F et al. Safety and immunogenicity of oral whole cell recombinant $B$ subunit cholera vaccine in Barranquilla, Colombia. Bull Pan Am Health Org 1995;29:312-21.

3. Clemens JD, Sack DA, Harris JR, Chakraborty J, Khan MR, Stanton BF, et al. Field trial of oral cholera vaccines in Bangladesh. Lancet 1986;2:1247.

4. Clemens JD, Stanton BF, Chakraborty J, Sack DA, Khan MR, Ahmed F et al. B subunit-whole cell and whole cell only oral vaccines against cholera: studies on reactogenicity and immunogenicity. J Infect Dis 1987;155:79-85.

5. Holmgren J, Svennerholm AM, Jertborn M, Clemens JD, Sack DA, Salenstedt R, et al. An 
oral B subunit: whole cell vaccine against cholera. Vaccine 1992;10:911-4.

6. Jertborn M, Svennerholm AM, Holmgren $\mathbf{J}$. Safety and immunogenicity of an oral recombinant cholera B subunit-whole cell vaccine in Swedish volunteers. Vaccine 1992;10:130-2.

7. Jertborn M, Svennerholm AM, Holmgren $J$. Immunological memory after immunization with oral cholera B subunit-whole-cell in Swedish volunteers. Vaccine 1994;12:1078-82.

8. Svennerholm AM, Jertborn M, Gothefors L, Karim AMMM, Sack DA, Holmgren J. Comparison of mucosal antitoxic and antibacterial immune responses after clinical and after oral immunization with combined B subunit-whole cell vaccine. J Infect Dis $1984 ; 149: 883-93$.

9. Castañeda E, Chinchilla M, Velandia M, de la $\mathrm{Hoz}$ F. Seguridad e inmunogenicidad de la vacuna oral contra el cólera: estudio en 20 voluntarios. Biomédica 1995; 15:54-8.

10. Migasena S, Desakorn V, Suntharasamai $\mathbf{P}$, Pitisuttitham P, Prayurahong B, Supanaranond W, et al. Immunogenicity of two formulations of oral cholera vaccine comprised of killed whole cell Vibrios and the B subunit of cholera toxin. Infect Immun 1989;57:117-20.

11. Kenny GE, Dunsmoor CL. Principles, problems, and strategies in the use of antigenic mixtures for the enzyme-linked immunosorbent assay. J Clin Microbiol 1983;17:655-65.

12. Sherarchi IC, Sever JL, Lee YJ, Castellano G, Madden DL. Evaluation of various plastic microtiter plates with measles, Toxoplasma, and gamma globulin antigens in enzyme-linked immunoabsorbent assays. J Clin Microbiol 1984;19:89-96. 